\title{
APRENDIZAGEM BASEADA EM PROJETO: UM MODELO DE INTERVENÇÃO E AVALIAÇÃO PARA EAD
}

\author{
Tania Rossi Garbin, Carlos Alberto Dainese \\ Universidade Federal de Ouro Preto - UFOP - Centro de Educação Aberta e a \\ Distância - CEAD/UFOP
}

trgarbin@cead.ufop.br, cdainese@cead.ufop.br

\begin{abstract}
Contemporary society is demanding a dynamic profile of professional, creative, reflective, competent and ethical. Whereas training courses distance learning, there can be different, the model developed ABP/EaD-Project Based Learning applied to EaD. This model aims to: (1) stimulate motivation, (2) promote learning focused on the student, (3) foster group work, (4) develop initiative and creativity, (5) develop communication skills, (6) critical thinking, (7) relate interdisciplinary content in an integrated way. For evaluation scale was developed EAABP/EaD based on Learning Strategies Scale developed and validated by Zerbini and Abbad (2008). The developed model was applied in a pilot study.
\end{abstract}

Keywords: Learning, Project Based Learning, Distance Education, Distance Education Management

Resumo. A sociedade contemporânea está exigindo dos profissionais um perfil dinâmico, criativo, reflexivo, competente e ético. Considerando que a formação em cursos EaD, não pode ser diferente, desenvolvemos o modelo ABP/EaDAprendizagem Baseada em Projeto aplicada a EaD. Este modelo tem como objetivo: (1) estimular a motivação; (2) promover a aprendizagem focada no aluno; (3) fomentar o trabalho em grupo; (4) desenvolver iniciativa e criatividade; (5) desenvolver capacidades de comunicação; (6) desenvolver o pensamento crítico; (7) relacionar conteúdos interdisciplinares de forma integrada. Para avaliação foi desenvolvido escala ABP/EaD, baseada na Escala de Estratégias de aprendizagem desenvolvida e validada por Zerbini e Abbad (2008). O modelo desenvolvido foi aplicado em um estudo piloto.

Palavras-chave: Aprendizagem; Aprendizagem Baseada em Projeto; Educação a Distancia; Gestão da EAD.

\section{Aprendizagem Baseada em Projeto}

A aprendizagem baseada em projeto oferece várias possibilidades. Surgiu no início do século $\mathrm{XX}$, desde sua origem, recebeu várias denominações, tais como: "projetos de trabalho, metodologia de projetos, metodologia de aprendizagem por projetos, pedagogia de projetos". $\mathrm{Na}$ aprendizagem por projeto o Método de Projetos é uma estratégia de ensino-aprendizagem que visa, por meio da investigação de um tema ou problema, vincular teoria e prática. Gera aprendizagem diversificada e em tempo real, inserida em novo contexto pedagógico no qual o aluno é agente na produção do conhecimento. Rompe com a imposição de conteúdos de forma rígida e pré-estabelecida, incorporando-os na medida em que se constituem como parte fundamental para o desenvolvimento do projeto. No Brasil, o método foi introduzido a partir do Movimento Escola Nova [Barbosa, Contijo e Santos 2013]. 
A aprendizagem baseada em projeto está pautada no principio da resolução de problemas, na prática efetiva dos envolvidos na situação de ensino-aprendizagem. Diferente da metodologia apoiada na transmissão de informações, esta metodologia não significa reproduzir, é fundamental que a aprendizagem ocorra de forma significativa de maneira ativa [Fagundes et al 2005].

Para Almeida e Prado (2003), na aprendizagem por projeto deve ocorrer a proposição de situações complexas, abertas e de enunciado impreciso, cuja resolução implica em mobilizar competências necessárias para aprender, fazendo, o que não se sabe fazer. Assim, os cenários devem partir de contextos significativos para os alunos de modo a motiva-los a buscar informações, estabelecer articulações com conhecimentos, tomar decisões e elaborar uma nova organização que permita superar o obstáculo ou desafio.

Segundo Valente (2005), o interesse do aluno pode ser determinado quando é utilizado como estratégias educacionais o desenvolvimento de projetos. O desenvolvimento de projetos pode auxiliar na motivação e no envolvimento do aluno, tornando a aprendizagem significativa.

Para ocorrer aprendizagem significativa o aluno precisa dar significado, sentido e funcionalidade ao que se aprende. A relação entre conhecimento e experiência auxilia o processo de aprendizagem. $\mathrm{Na}$ aprendizagem significativa, o aluno interage com a cultura sistematizada de forma ativa, como principal ator do processo de construção do conhecimento.

Para Libâneo (1987), o professor deve oferecer aos alunos novos desafios e promover a oportunidade de novas aquisições. Para isso, é necessário um trabalho de continuidade e ruptura em relação aos conhecimentos que o aluno traz. Identificar as habilidades e conhecimento que o aluno possui, pode facilitar o planejamento, pois o conteúdo novo deve apoiar-se numa estrutura cognitiva já existente. Relacionar os novos conteúdos à experiência do aluno pode provocar novas necessidades e desafios.

$\mathrm{Na}$ aprendizagem por projeto, temos então a redefinição do papel de três importantes agentes no contexto educacional: o conhecimento, tido como bem de valor; o aluno, principal responsável pela construção do seu saber e o professor/tutor, mediador entre os dois primeiros. Esta redefinição atribui ao processo ensino-aprendizagem características inovadoras: participação ativa dos alunos no planejamento e execução de suas atividades, utilização de novos recursos de ensino, concepção do professor pesquisador [Barbosa, Contijo e Santos 2013].

Para Ziede, Meier e Seidel (2007), a situação de projetos de aprendizagem pode favorecer a aprendizagem de cooperação, através das trocas e interações. A proposta é aprender por meio de procedimentos que desenvolvam a própria capacidade de continuar aprendendo, num processo construtivo e simultâneo de questionar-se, encontrar certezas e reconstruí-las em novas certezas.

Papert (1997) considera que o papel do professor é criar às condições a invenção, em lugar de fornecer conhecimentos já consolidados. O aluno deve construir conhecimentos novos em qualquer situação.

Dessa forma, foi desenvolvido um ambiente de aprendizagem, que tem como princípio que o processo de aprendizagem deve estar centrado no aluno e nas suas necessidades, dispondo de recursos e de princípios embasados na teoria sócio-histórica. Assim, numa concepção interacionista/construtivista permite aos aprendizes, a partir da interação com objetos físico e social a construção de conhecimento. 


\section{Modelo Aprendizagem Baseada em Projeto - ABP/EaD}

Ao propormos uma prática pedagógica baseada no desenvolvimento de aprendizagem por investigação estamos falando em deixar de lado a rigidez dos conteúdos tidos como universais e passar a trabalhar a partir de projetos originados das curiosidades e indagações dos alunos frente à realidade na qual estão inseridos.

O desenvolvimento das atividades que oferecem a possibilidade para a realização da aprendizagem por projeto pode ser realizado no ambiente de aprendizagem, plataforma, e no polo de apoio presencial. O desenvolvimento de atividades presenciais grupais oferece grande incentivo para a criatividade, inovação e relacionamento interpessoal e a plataforma auxilia a interlocução e a realização das atividades, pois as ferramentas assíncronas permitem a utilização do tempo conforme cada necessidade especifica e quando os grupos precisam articulações diretas podem ser utilizadas ferramentas síncronas. Tanto no ambiente virtual de aprendizagem como no ambiente presencial, o papel do mediador é fundamental para a promoção da articulação e o desenvolvimento da aprendizagem por investigação. A seguir as estratégias/ferramentas que podem ser utilizadas como suporte no ambiente virtual e no polo de apoio presencial.

Quadro 1. Ferramentas e metodologia para o desenvolvimento de atividades grupais.

\begin{tabular}{|l|l|}
\hline Plataforma & Polo de apoio presencial \\
\hline Wiki (ferramenta assíncrona) & Reuniões \\
\hline Fórum (ferramenta assíncrona) & Seminários \\
\hline Chat (ferramenta síncrona) & Dinâmicas de grupo \\
\hline Envio de Arquivo & Apresentações \\
\hline
\end{tabular}

A escolha de ferramentas deve considerar o objetivo proposto, assim como a proposição de atividades presenciais. Para garantir a oportunidade de realização de aprendizagem significativa, devem ser oferecidas condições que favoreçam os alunos a construir novos processos. O aluno deve ser ativo, deve ter a possibilidade de propor e criar. A seguir no Quadro 2 são apresentadas informações sobre as condições que devem ser oferecidas e o desempenho esperado.

Quadro 2. Atividades, condições oferecidas e desempenho esperado.

\begin{tabular}{|c|c|c|}
\hline $\begin{array}{l}\text { Atividades } \\
\text { propostas }\end{array}$ & $\begin{array}{l}\text { Condições oferecidas } \\
\text { (professor/tutor- como articulador) } \\
\text { Definição de etapas, regras, direção e } \\
\text { atividades. }\end{array}$ & $\begin{array}{l}\text { Desempenho esperado } \\
\text { (aluno - como construtor) }\end{array}$ \\
\hline $\begin{array}{l}\text { Apresentação - } \\
\text { objetivo - } \\
\text { cronograma de } \\
\text { trabalho }\end{array}$ & $\begin{array}{l}\text { Sistematização de informações: } \\
\text { - } \quad \text { Plataforma de aprendizagem; } \\
\text { - } \quad \text { Material digital; } \\
\text { - } \quad \text { Videoconferência; } \\
\text { - } \quad \text { Links para portais periódicos, } \\
\text { revistas e material acadêmico; } \\
\text { - } \quad \text { Bibliografia. }\end{array}$ & Receptor/propositor \\
\hline $\begin{array}{l}\text { Definição do } \\
\text { problema de } \\
\text { investigação }\end{array}$ & $\begin{array}{l}\text { Apresentação de necessidade } \\
\text { Propor Atividade } \\
\text { Contexto - experiência profissional - }\end{array}$ & $\begin{array}{l}\text { Ativo/propositor } \\
\text { Identificação; definição de grupo; } \\
\text { levantamento de necessidade; definição } \\
\text { de tema e objetivo de investigação. }\end{array}$ \\
\hline $\begin{array}{l}\text { Definição da } \\
\text { metodologia de } \\
\text { investigação }\end{array}$ & $\begin{array}{l}\text { Apresentação de necessidade } \\
\text { Propor atividade - orientar }\end{array}$ & $\begin{array}{l}\text { Ativo /propositor } \\
\text { Apresentar proposta }\end{array}$ \\
\hline Coleta de & Propor atividade - orientar & Organiza, sistematiza, analisa, descreve \\
\hline
\end{tabular}




\begin{tabular}{|l|l|l|}
\hline $\begin{array}{l}\text { informação - } \\
\text { sistematização de } \\
\text { informação }\end{array}$ & e apresenta. \\
\hline Resultado & Propor atividade, apresentação. & Criatividade e iniciativa, participação. \\
\hline
\end{tabular}

$\mathrm{Na}$ concepção da aprendizagem por projetos, os alunos dividem-se em grupos, cabendo a cada grupo investigar e construir conhecimento sobre um tema. A escolha do tema é norteada pela curiosidade visando com isso tornar a aprendizagem mais significativa possível. O desenvolvimento de atividades grupais em cursos de modalidade a distancia deve ser bem planejado, o tempo para a realização de cada etapa deve considerar as diversas variáveis que podem interferir no processo de aprendizagem, conforme Quadro 3.

\section{Quadro 3. Variáveis e condições oferecidas.}

\begin{tabular}{|c|c|c|}
\hline Variáveis & Variáveis dependentes & Condicões \\
\hline $\begin{array}{l}\text { Local de } \\
\text { residência }\end{array}$ & $\begin{array}{l}\text { Proximidade do polo de apoio } \\
\text { presencial }\end{array}$ & $\begin{array}{l}\text { Composição do grupo deve sempre respeitar os } \\
\text { alunos, nunca por imposição do professor/tutor }\end{array}$ \\
\hline $\begin{array}{l}\text { Atividades } \\
\text { profissionais }\end{array}$ & $\begin{array}{l}\text { Horário de trabalho em turno; } \\
\text { horário destinado por escala; mais } \\
\text { de uma jornada de trabalho; }\end{array}$ & $\begin{array}{l}\text { Atividades profissionais e horários de trabalho } \\
\text { precisam ser apresentados para o grupo definir } \\
\text { estratégias para o desenvolvimento do trabalho }\end{array}$ \\
\hline $\begin{array}{l}\text { Tempo disponível } \\
\text { para atividades } \\
\text { presenciais }\end{array}$ & $\begin{array}{l}\text { Horário compatível com a maioria } \\
\text { para realização de reuniões e } \\
\text { manter os horários definidos pelo } \\
\text { calendário oficial do curso para } \\
\text { não prejudicar a participação dos } \\
\text { alunos. }\end{array}$ & $\begin{array}{l}\text { O calendário acadêmico deve prever a } \\
\text { realização de atividade presenciais com } \\
\text { antecedência, no inicio de cada período letivo. } \\
\text { As reuniões para realização das atividades do } \\
\text { grupo devem ser agendadas pelo grupo, } \\
\text { respeitando os alunos e a infraestrutura do polo } \\
\text { de apoio presencial. }\end{array}$ \\
\hline $\begin{array}{l}\text { Tempo disponível } \\
\text { para atividades a } \\
\text { distancia }\end{array}$ & $\begin{array}{l}\text { O grupo deve programar ações a } \\
\text { partir do planejamento e } \\
\text { condições apresentadas pelo } \\
\text { professor/tutor. }\end{array}$ & $\begin{array}{l}\text { O período para o desenvolvimento das } \\
\text { atividades a distancia deve ser compatível com } \\
\text { a especificidade e complexidade das atividades. } \\
\text { Deve ser oferecida aos alunos a possibilidade } \\
\text { de utilizar ferramentas para auxilio/suporte para } \\
\text { o desenvolvimento das atividades. }\end{array}$ \\
\hline $\begin{array}{l}\text { Domínio da } \\
\text { tecnologia - } \\
\text { ferramentas/softw } \\
\text { are }\end{array}$ & $\begin{array}{l}\text { Apresentar ferramentas e software } \\
\text { compatível com o objetivo e } \\
\text { habilidades dos alunos }\end{array}$ & $\begin{array}{l}\text { Definir ferramentas e softwares que possam } \\
\text { auxiliar o desenvolvimento da } \\
\text { investigação/projeto e que os alunos tenham } \\
\text { domínio para a utilização. }\end{array}$ \\
\hline $\begin{array}{l}\text { Organização, } \\
\text { liderança }\end{array}$ & Respeito à dinâmica grupal & $\begin{array}{l}\text { O grupo deve definir os papeis que cada aluno } \\
\text { vai desempenhar para o desenvolvimento do } \\
\text { projeto. }\end{array}$ \\
\hline Acesso à rede & $\begin{array}{l}\text { Tecnologia, rede, equipamentos e } \\
\text { suporte. }\end{array}$ & $\begin{array}{l}\text { As atividades propostas devem considerar o } \\
\text { acesso dos participantes a rede e os } \\
\text { equipamentos disponíveis para o } \\
\text { desenvolvimento das atividades }\end{array}$ \\
\hline $\begin{array}{l}\text { Habilidades e } \\
\text { competências }\end{array}$ & Trabalho em grupo. & $\begin{array}{l}\text { Devem ser identificadas, pelo professor/tutor, } \\
\text { as habilidades necessárias para o } \\
\text { desenvolvimento das atividades grupais. }\end{array}$ \\
\hline
\end{tabular}

Cabe ao professor/tutor verificar a possibilidade real para a proposição de uma atividade grupal que visa à aprendizagem por investigação ou projeto. $\mathrm{O}$ êxito ou não do processo não depende somente do aluno, ou somente do professor/tutor. A articulação entre as competências, necessidades e condições dos alunos e das variáveis de infraestrutura e apoio técnico e pedagógico podem favorecer o desenvolvimento das atividades e auxiliar no aprendizado significativo. Na Figura 1, pode ser verificada a representação do modelo. 


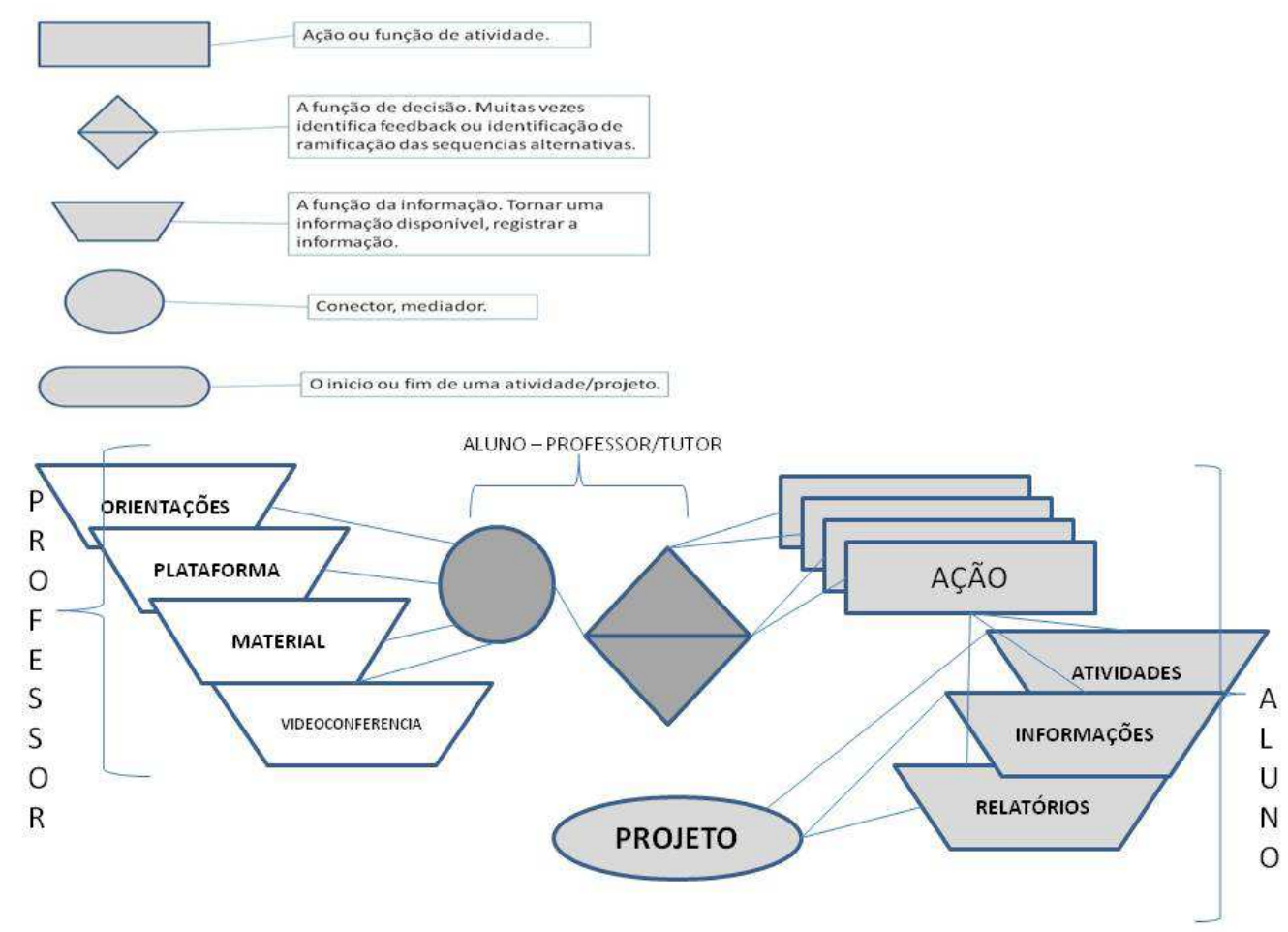

Figura 1. Modelo de Aprendizagem por Projeto

Na Figura 1, podem ser observadas representações das ações do professor/tutor e aluno, a articulação para o desenvolvimento do projeto de aprendizagem. Nessa abordagem, os projetos se constituem em planos de trabalho e conjunto de atividades que podem tornar o processo de aprendizagem mais dinâmico, significativo e interessante para o aluno, deixando de existir a imposição dos conteúdos de maneira autoritária. A partir da escolha de um tema, o aluno realiza pesquisas, investiga, registra dados, formula hipóteses, analisa, aplica e avalia o projeto construído [Fagundes et al. 2006].

No modelo proposto, a aprendizagem baseada em projeto, o professor oferece o suporte através da plataforma, orientações, materiais e vídeo e web conferencia para os alunos. Quando o aluno interage com a tecnologia, neste caso com a plataforma de aprendizagem ocorre o ciclo de ações descrição-execução-reflexão-depuração, que segundo Valente (2005) essas ações criam oportunidades de construção de conhecimento e, à medida que o ciclo se repete, cria conhecimentos, formando o que foi denominado de "espiral de aprendizagem".

Na educação problematizadora, busca-se interpretar a realidade voltando-se à criação de espaços contra-hegemônicos e contestatórios que possibilitem crítica, algumas vezes radical, à realidade estudada. Constatando e conhecendo os problemas, tornamo-nos capazes de intervir na realidade.

Para avaliação do modelo $\mathrm{ABP} / \mathrm{EaD}$ foi adaptada a escala, desenvolvida e validada, de Zerbini e Abbad (2008). O instrumento (EABP/EaD- Escala Aprendizagem Baseada em Projeto para Educação a Distancia) contem 33 itens utilizando para resposta escala do tipo Likert (0- Nunca a 10 - Sempre). Os itens são divididos em três fatores sendo: Controle da emoção; Controle da motivação; Monitoramento da compreensão. A seguir apresentamos a escala. 
II Congresso Brasileiro de Informática na Educação (CBIE 2013)

Workshops (WCBIE 2013)

Tabela 1. Escala para Avaliação da Aprendizagem Baseada em Projeto -EAABP/EaD.

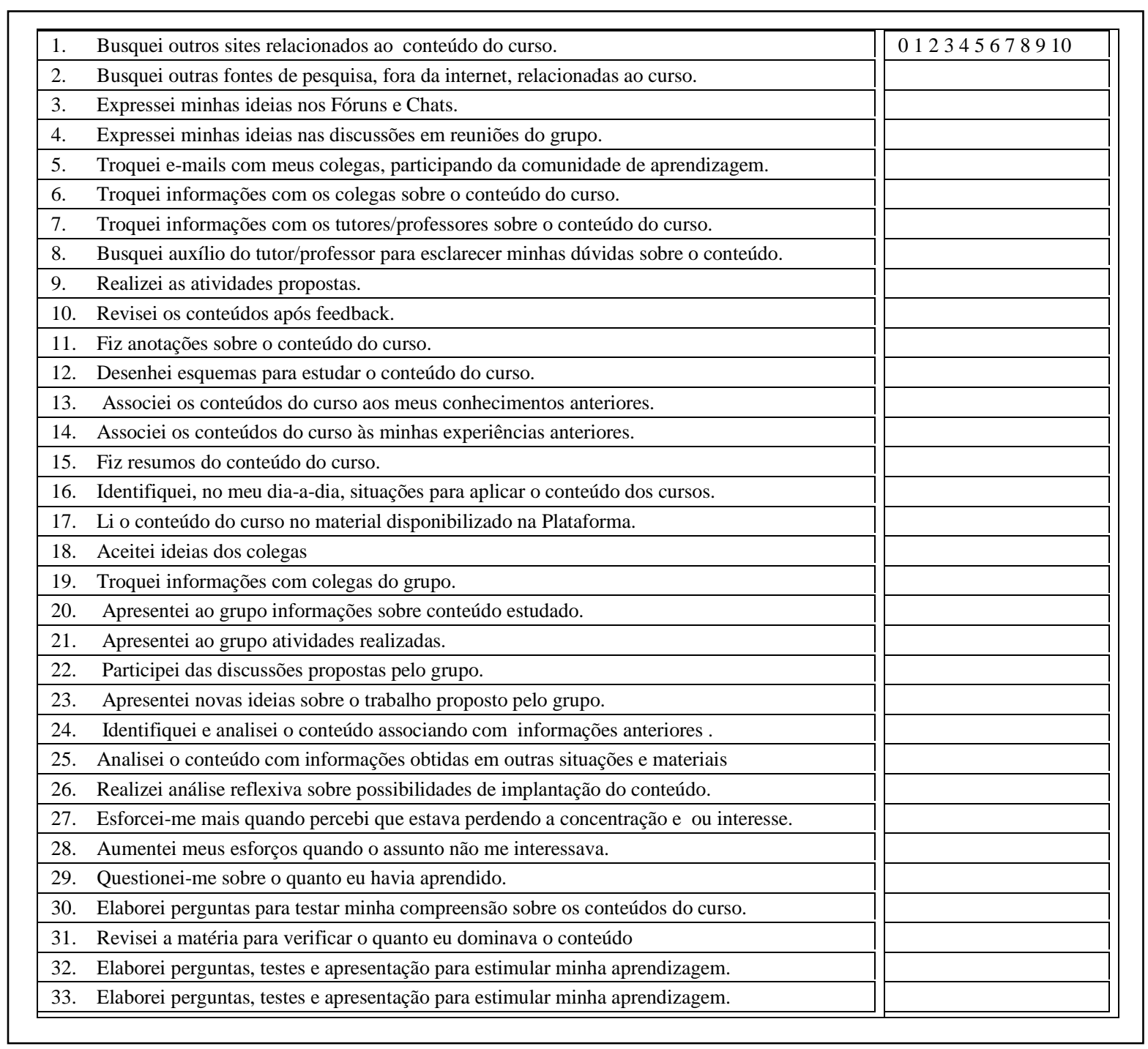

Zerbini e Abbad (2008) apresentam informações sobre o instrumento desenvolvido por Warr e Allan (1998) e destacam duas categorias nas estratégias de aprendizagem: as estratégias primárias $\mathrm{e}$ as auto-regulatórias. As primárias afetam $\mathrm{o}$ processo de aprendizagem nas etapas de seleção, armazenamento e recuperação de informações e também são chamadas de estratégias cognitivas. Estratégias auto-regulatórias compreendem a motivação do indivíduo para aprender, a auto-gestão de esforços e de automonitoramento do progresso durante a aprendizagem, bem como o controle de ansiedade diante de determinadas situações, que estariam dispersando a atenção do aprendiz; também são conhecidas como estratégias de suporte. Conforme pode ser observado na escala $\mathrm{ABP} / \mathrm{EAD}$, dos 33 itens, identificamos 7 grupos de objetivos (Quadro 4) que estão relacionados com estratégias primárias e de auto-regulação. 
Quadro 4. Objetivos relacionados à aprendizagem baseada em projeto.

\begin{tabular}{|l|l|l|l|}
\hline Objetivos & $\begin{array}{l}\text { Intervenção } \\
\text { (Figura 1) }\end{array}$ & $\begin{array}{l}\text { Ação Aluno } \\
\text { (Figura 1) }\end{array}$ & $\begin{array}{l}\text { Critérios Avaliação } \\
\text { (Escala EAABP/EaD) }\end{array}$ \\
\hline $\begin{array}{l}\text { 1) estimular a motivação; } \\
\text { f) promovada no aluno; }\end{array}$ & $\begin{array}{l}\text { 3) fomentar o trabalho em } \\
\text { grupo }\end{array}$ \\
\hline $\begin{array}{l}\text { 4) desenvolver iniciativa e } \\
\text { criatividade }\end{array}$ & $\begin{array}{l}\text { 5) desenvolver capacidades } \\
\text { de comunicação }\end{array}$ \\
\hline $\begin{array}{l}\text { 6) desenvolver o pensamento } \\
\text { crítico } \\
\text { interdisciplinares de forma }\end{array}$
\end{tabular}

As atividades, informações, materiais e orientações apresentadas na disciplina foram organizados a partir de 7 grandes objetivos (Quadro 4). A partir do modelo apresentado na Figura 1, é possível verificar a representação do modelo proposto indicado nas relações entre as condições oferecidas e ações esperadas. A interação e mediação entre condições oferecidas e desempenho esperado ocorrem nas ações dos alunos, professores e tutores e podem ser verificadas na utilização da Escala de Avaliação da Aprendizagem Baseada em Projeto (EAABP/EaD) e também através do desempenho dos alunos na Plataforma e no resultado final "Projeto".

A partir da proposta da metodologia da aprendizagem baseada em projeto (ABP/EaD), foi desenvolvido um estudo piloto aplicado aos cursos de Bacharelado em Administração Pública e Licenciatura em Geografia, que serão apresentados a seguir.

\section{Aplicação do Modelo ABP/EaD}

O modelo ABP/EAD desenvolvido foi aplicado em duas disciplinas sendo: Seminário Temático: Cultura e Instituições Públicas do curso de Administração Pública, em 08 Polos/Turmas e Psicologia da Educação do Curso de Licenciatura em Geografia em 4 Polos/Turmas. Participaram 14 tutores, 3 professores e 250 alunos.

O procedimento utilizado foi apresentar no inicio da oferta da disciplina informações sobre objetivo, materiais e links onde os alunos poderiam obter informações sobre conteúdos relacionados às temáticas centrais. Foram oferecidas informações relacionadas ao cronograma assim como as exigências especificas para o desenvolvimento das disciplinas. Para as orientações gerais foi agendada uma videoconferência onde os alunos interagiram em tempo real. Esta videoconferência foi gravada e disponibilizada para os alunos como consulta. Alem 
dos materiais específicos sobre os diferentes temas/conteúdos das disciplinas foram disponibilizadas orientações gerais sobre o desenvolvimento das atividades previstas. A exigência das disciplinas é que deveria ser realizado um trabalho em grupo com uma temática relacionada ao conteúdo da disciplina que o grupo deveria definir desenvolver e apresentar. $\mathrm{Na}$ Figura 2 pode ser verificadas a Plataforma de Aprendizagem e imagem da videoconferência.
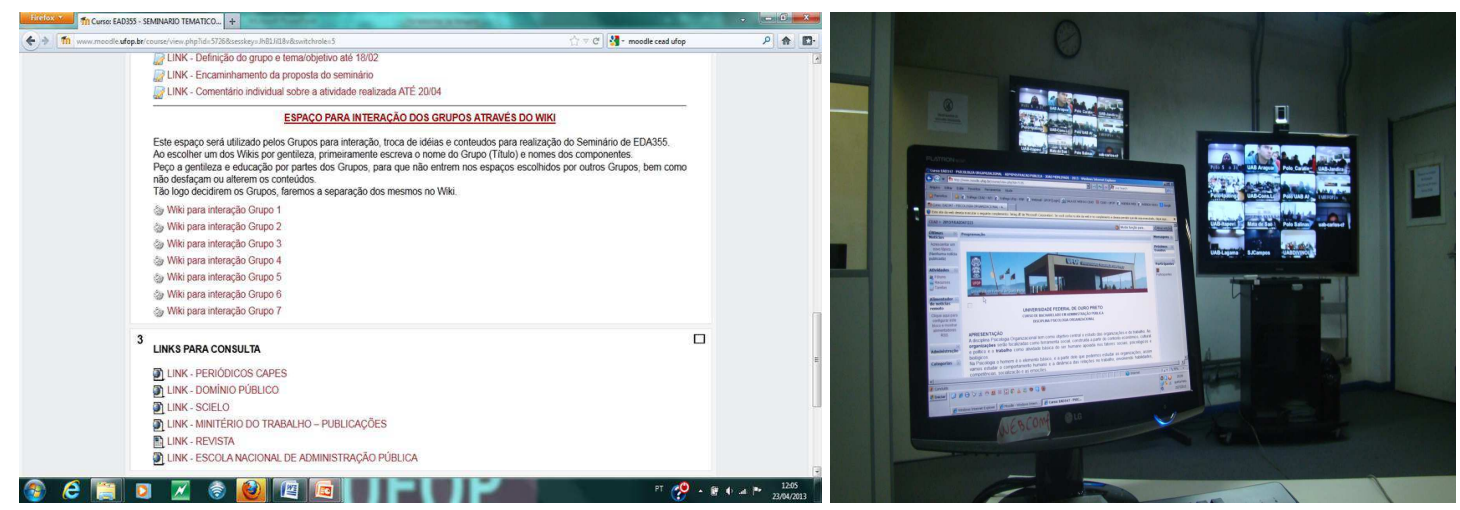

Figura 2. Ambiente de Aprendizagem do Curso de Administração Pública e Videoconferência.

Pode ser observado que foi disponibilizada a ferramenta Wiki para cada grupo e links para consulta. Alem destas ferramentas foi utilizado link para arquivo, Fórum e Chat. Os grupos encaminharam através da Plataforma informações sobre as diferentes etapas para o desenvolvimento do projeto. Também foram realizadas reuniões no polo de apoio presencial. Em todas as etapas ocorreu a mediação dos tutores com o objetivo de auxiliar os encaminhamentos para o desenvolvimento dos projetos. Para Almeida e Valente (2012), o trabalho de investigação realizado pelos alunos pode ser descrito e documentado em um repositório tornando o aluno ativo na situação de ensino valorizando o desenvolvimento do conhecimento e a utilização da tecnologia, desta forma no ambiente funcionou como repositório.

A avaliação da disciplina foi realizada a partir do desempenho apresentado na Plataforma, dos projetos e do instrumento EAABP/EaD. Os grupos promoveram atividades acadêmicas e atividades culturais em todos os polos tutores presenciais e tutores a distancia acompanharam as atividades. Foram utilizadas folhas de registro para auxiliar $o$ acompanhamento e avaliação e o formulário contendo a escala EAABP/EaD, sendo esta aplicada em 235 alunos. As respostas dos participantes aos 33 itens da escala apresentaram 39 casos extremos univariados e 19 casos extremos multivariados, os quais foram retirados do arquivo de dados totalizando 183 casos. Algumas características foram analisadas: identificou-se a presença de relações lineares entre variáveis, e foram identificados três pares de itens correlacionados entre si, com coeficiente de correção variando de 0,80 a 0,82 . Após a análise de presença de multicolinearidade, foram retirados da escala três itens do instrumento (itens 27, 28 e 29). Para realizar a análise da matriz de covariância em termos fatorabilidade, foi analisado o tamanho das correlações da amostra. Apesar de existirem valores inferiores a 0,28 , foram identificados, em $50 \%$ dos casos, valores de correlação superior a 0,28 indicando que provavelmente a matriz é fatorizável. Vários foram os fatores analisados considerando a correlação e consistência do instrumento. A seguir na Figura 3 podem ser observados alguns projetos. 

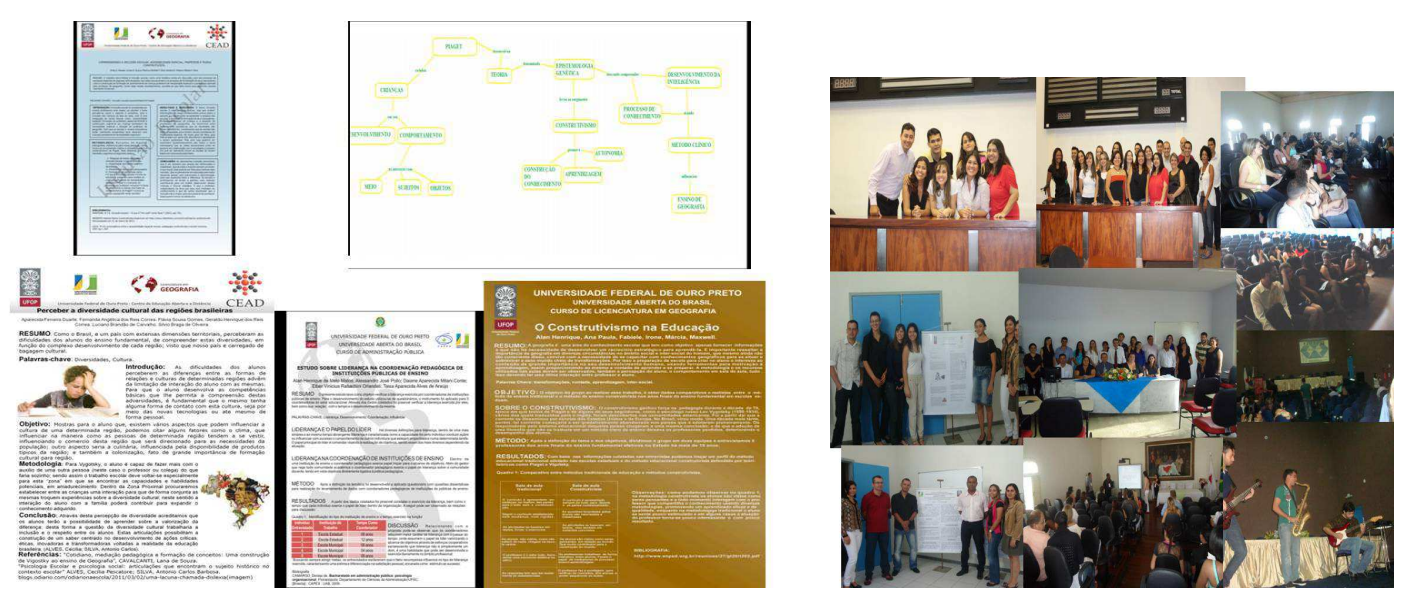

Figura 3. Resultados dos projetos e seminários realizados nos Polos de Apoio Presencial.

Os grupos tiveram autonomia para decidir sobre objetivo/tema, método, e apresentação com base nas informações apresentadas na Plataforma de Aprendizagem. Todas as orientações para o desenvolvimento estavam disponíveis desde o inicio da disciplina, incluindo materiais como artigos, links, vídeos e materiais de orientação. Os grupos utilizaram para apresentar os resultados do projeto desenvolvido mapa conceitual, apresentação em painel, discussões e a realização de seminários (Figura 3).

\section{Discussão}

Para Brito, Tavares e Menezes (2002), o desenvolvimento de um projeto de aprendizagem consiste na busca por informações que esclareçam as indagações do aluno sobre a sua realidade, associada à apresentada pelo professor na situação de aprendizagem. Essas indagações se manifestam por inquietações advindas de suas vivências e necessidades em conhecer e explicar os fenômenos. O objetivo é o desenvolvimento de um processo de aprendizagem que alcance a construção de novos conhecimentos, em que o aprendiz possa sistematizar informações ampliando sua rede de significações, possa reestruturar o raciocínio lógico sobre os novos significados enquanto elabora sínteses de respostas descritivas e explicativas para sua curiosidade.

Em um projeto, a responsabilidade e a autonomia dos aprendizes são essenciais. Os aluno são co-responsáveis pelo trabalho e pelas escolhas realizadas ao longo do desenvolvimento do projeto. Em geral, essas escolhas são realizadas em grupo, motivo pelo qual a cooperação está também quase sempre associada ao trabalho de projetos. A cooperação é necessária uma vez que o desenvolvimento de um projeto envolve complexidade e resolução de problemas. O objetivo central do projeto constitui um problema que exige o planejamento e a execução de uma ou mais atividades para sua resolução.

Foi possível constatar que as atividades realizadas para o desenvolvimento do projeto foram desenvolvidas de forma satisfatória. Os alunos demonstraram interesse, motivação, autonomia, criatividade e habilidades acadêmicas para apresentação oral e escrita dos resultados alcançados.

A partir da experiência realizada e os dados da literatura verificamos que o processo de aprendizagem pode ser realizado por modelos não lineares, utilizando estratégias de integração, questionamento e novas sínteses dos conteúdos aprendidos e informações oferecidas, com estratégias individuais e grupais.

Pretendemos em trabalhos futuros, verificar os processos de aprendizagem em disciplinas de cálculo e administração financeira aplicando o modelo $\mathrm{ABP} / \mathrm{EaD}$ e realizar 
avaliação a partir da análise estatística da escala desenvolvida (EAABP/EaD) para possibilitar a validação.

\section{Referências}

ALMEIDA, M.E.B; PRADO, M.E.B.Criando Situações De Aprendizagem Colaborativa. In: Workshop em Informática na Educação -WIE, 2003. p.53-60.

ALMEIDA, M.E.B.; VALENTE, J.A. (2012)Web Currículo: Integração de Mídias nas Escolas com Base na Investigação de Fatos Científicos para o Fazer Científico. In: SANTOS, E. Currículos- Teorias e Práticas e Práticas. Rio de Janeiro: LTC, p.121-136.

BARBOSA, E.F.; CONTIJO, A.F.; SANTOS, F.F. (2013) Inovações pedagógicas em educação profissional: uma experiência de utilização do método de projetos na formação de competências. http://www.senac.br/INFORMATIVO/BTS/302/boltec302d.htm. Acesso 19 fevereiro 2013.

BRITO, S.R.; TAVARES, O.L.; MENEZES, C.S. (2002) MEDIADOR - Um ambiente para aprendizagem orientada a projetos com suporte inteligente à mediação XIII Simpósio Brasileiro de Informática na Educação - SBIE - UNISINOS.

FAGUNDES, L.C; BASSO,M.V; NEVADO,R.A.; BITENCOURT, J.V; MENEZES, C.S.(2005) AMADIS - Um Ambiente Virtual para apoio ao Desenvolvimento de Projetos de Aprendizagem Workshop em Informática na Educação (SBIE).

FAGUNDES, L.C.; NEVADO,R.A.; BASSO,M.V.; BITENCOURT, J.V.; MENEZES, C.S.; MONTEIRO, V.C.P.C. (2006) Projetos de Aprendizagem - Uma experiência mediada por ambientes telemáticos. Revista Brasileira de Informática na Educação.

LIBÂNEO, J. C. (1987) Democratização da escola pública. A pedagogia crítico-social dos conteúdos. São Paulo: Loyola.

PAPERT, S. (1997) A família em rede: Ultrapassando a barreira digital entre gerações. Tad. Fernando José Silva Nunes; Fernando Augusto Bensabat Lacerda e Melo. Lisboa: Relógios D’Agua Editores, p.278.

VALENTE, J. A. (2005) A Espiral da Espiral de Aprendizagem: o processo de compreensão do papel das tecnologias de informação e comunicação na educação. Campinas: SP. Tese (Livre Docência) - Universidade Estadual de Campinas. Instituto de Artes.

ZERBINI, T.; ABBAD, G. (2008) Estratégias de aprendizagem em curso a distância: validação de uma escala. In: Psico-USF, p.177-187.

ZIEDE, M.L.; MEIER, M.; SEIDEL, S. (2007) Tuti, a cientista: um objeto desenvolvido para construção de projetos de aprendizagem. In: Nevado, R.A.; Carvalho, M.J.S.; Menezes, C.S. Aprendizagem em rede na educação à distância: estudos e recursos para formação de professores. Porto Alegre: Ricardo Lenz, p.121-136. 